\title{
On the Self-regulated Learning Ability of Students and Its Development
}

\author{
Jisheng $\mathrm{He}^{\dagger}$, Ling $\mathrm{He}^{\dagger}$, Naizhu Huang *, Jiaming Zhong *, Linzi Qin \\ Xiangnan University, Chenzhou, Hunan, 423000 \\ $\uparrow$ The first two authors contributed equally to this paper and should be considered co-first authors. \\ *Corresponding author: Naizhu Huang, Jiaming Zhong
}

\begin{abstract}
It is crucial for students to bear the ability of self-access for effective learning. Abilities of students' self-access should be trained on basis of the connotation of self-access ability, with the start of training students' self-direction, self-monitoring, self-regulation and self-accessment abilities. Ways and measurements of self-access training are to be made considering the relationship between knowledge, skills and abilities, and following the theoretical basis of students' self-access ability training. Cognition guidance measures are best choice.
\end{abstract}

Keywords: Students; abilities of self-access; cultivation

\section{Introduction}

Self-regulated learning (SRL) ability is the key to effective learning. Since the 1990s, developing students' SRL has been an important educational goal in countries around the world, and studies ranging from practical exploration to theoretical summary have been conducted. Through a full-course follow-up study of online education teaching in Tsinghua University during the spring 2020 semester, the research topic group of online education in Tsinghua University found that "students with high SRL are more active in their interactive behavior online and have higher scores in self-reporting of learning effect",[1] which once again confirms that SRL is positively correlated with academic performance in the learning environment mediated by technology. What is worrying is that many pupils and students in China lack the ability of SRL, and at the same time, family and school teachers also lack the attention and cultivation of their SRL. Especially, during the COVID-19 outbreak, some students who lacked SRL became "marginal people" in online learning. The cultivation of students' SRL has become a great challenge for education, especially online education, so how to recognize and cultivate students' SRL is a major issue worthy of continuous exploration.

\section{Definition of SRL}

Educational experts at home and abroad have defined SRL from different angles, including "process (activity) theory" (Pintrich, Zimmerman, Han Qinglin, et al.); "mode theory" (Yu Wensen, Cheng Xiaotang, et al.), "ability theory" (Holec, et al.) and so on. According to the view of "process (activity) theory", SRL is an active and constructive learning process for students (Pintrich, 2000), and a self-directed feedback loop process for learners to adjust their learning activities repeatedly according to these feedbacks (Zimmerman, 1900), with which the author agrees. SRL is a process (or activity), just like "teaching", also is a process (or activity). The effectiveness of teaching activities is related to such factors as teaching concept, method and ability, while the activity of SRL is affected by such factors as consciousness, habit, ability and method. Therefore, cultivating students' SRL is to cultivate students' awareness, habits, abilities and methods of autonomous learning, of which the cultivation of autonomous learning ability is the core content.

The SRL was first proposed by Holec (1981), who defined "Self-regulated" as "the ability to be responsible for

ISSN: 0010-8189

(C) CONVERTER 2020

www.converter-magazine.info 
self-learning", which is embodied in the determination of learning objectives, the determination of learning content and progress, the selection of learning methods and strategies, the monitoring of learning process, and the evaluation of learning effect.

Arnold (1999) pointed out that SRL consists of psychological-social support and technical support. Psychological-social support refers to motivation and its influencing factors. Technical support refers to the ability to train learners to set goals, select materials, methods, tasks, and perform tasks, self-monitoring capabilities, selection evaluation criteria, and self-evaluation capabilities.

Little (1991) defines SRL as three abilities: the ability to carry out objective and critical reflection, the ability to make decisions and the ability to take independent actions.

Ji Wenguang (2020) constructed and analyzed the "rocket model" of SRL from the perspective of ability, motivation and resistance by combining the perspective of learning ability and learning motivation[2].

So, what is SRL? Simply speaking, it is a kind of learning ability shown in the autonomous learning activities. According to psychology, ability is a necessary individual psychological characteristic for a person to complete an activity and a necessary condition for a task to be completed smoothly. Therefore, SRL refers to the sum of various psychological qualities for a learner to complete an autonomous learning task successfully, which is a comprehensive ability to survive and develop continuously not only psychological but also social.

Since students' SRL is not equal to adults' SRL, the concept of students' SRL is different from that of adults.

According to the process (activity) theory, SRL explains the essence of autonomous learning from the whole process of learning. Pang Weiguo thinks that a student realizes SRL if he/she can set learning goals, make learning plans, prepare for learning before learning activities, monitor, feedback and adjust his/her learning progress and learning methods, and check, summarize, evaluate and remedy his/her learning results after learning activities in a self-regulated way[3].

According to the above viewpoints, students' SRL refers to the sum of various psychological qualities of students successfully completing autonomous learning tasks, including self-direction ability, self-monitoring ability, self-regulation ability and self-evaluation ability, in which self-direction ability includes the ability to set goals and plans, self-monitoring ability includes self-examination and thought control ability, self-regulation ability includes self-feedback and self-remedy ability, and self-evaluation ability includes self-reflection and self-summary ability.

\section{Structure of SRL}

It is believed that SRL is a special learning ability based on cognitive ability and manifested in the learning activities of specific subjects. Based on the definition above, the structure of SRL is analyzed as follows:

(1)Self-direction ability: It refers to students' ability to set specific learning objectives, make detailed learning plans and determine specific learning contents after analyzing learning tasks. The so-called learning objective refers to the expected results of students' learning activities, which can stimulate, guide and regulate students' learning activities. It is composed of a series of goal groups, which include the total learning goal, stage goal, course goal, class time goal and so on. Students can discover their own learning deficiencies and transform them into clear learning goals, and formulate learning plans according to the learning goals, determine the specific learning content and learning time (even learning location), which is, solve the problem of "what to learn, when to learn, where to learn", which is the prerequisite for starting SRL. Only in this way can students avoid blindness and enhance their learning consciousness, thus improving the quality of learning. Therefore, self-orientation ability is very important, which is the primary ability that students should have in SRL.

ISSN: 0010-8189

(C) CONVERTER 2020

www.converter-magazine.info 
(2) Self-monitoring and self-regulation ability: Self-monitoring and self-regulation are closely integrated processes, which refer to students' ability to actively plan, check, evaluate, feedback, control and adjust learning activities in the whole learning process, so as to ensure that learning can achieve the expected learning goals. This ability is the most advanced component of the learning activities. It is not only the controlling executor of the learning activity, but also the internal mechanism for the development of SRL.

Not being supervised by others, students monitor their learning by themselves, constantly discover and analyze the problems and their causes in learning, and revise learning action accordingly. Self-monitoring and adjustment abilities are the key to whether students can achieve the expected goals in their independent learning. The self-monitoring and adjustment of learning is a metacognitive process that points to the learning process, and is the basic component process of SRL.

(3) Self-evaluation ability: It refers to the ability of students to judge their learning efficiency according to the observation and record of previous performance and results, including self-reflection and self-summary ability, and specifically including learning motivation evaluation, learning attitude evaluation, learning method evaluation and learning result evaluation. Through self-evaluationA good learner can have a comprehensive analysis of his/her progress and problems in learning.

\section{SRL Development}

SRL is an important learning ability that students should have, which is not born with it, but acquired by continuously developing and improving students' self-awareness and long-term learning practice on the basis of their educational experience, which requires teachers' "educational intervention" (Candy, 1991). That is to say, students' $\mathrm{SRL}$ is formed under the training and guidance of teachers.

According to the fact that knowledge and skills are the basis of ability, to develop SRL, it is essentia to enable students to master the relevant knowledge of SRL and train students to learn autonomously. According to the theory of cognitive constructivism, students can master metacognitive knowledge and train metacognitive skills through two methods: strategy teaching and situational simulation.

Strategy teaching is a way for teachers to teach students learning strategies through teaching, so as to solve the problems of students' low level of metacognition and lack of study strategies and methods. Learning strategies fall into two categories: one is general learning strategies, which are suitable for learning in any subject, such as planning and managing learning time, and the other is specific learning strategies, which are used in specific learning contents, such as taking notes. Zimmerma and Martinez-pons(1988) found ten kinds of learning strategies commonly used by middle school students through interviews, and that the use of students' SRL strategies has a high correlation with academic achievement[4]. Therefore, teachers should teach students various general and specific learning strategies as much as possible in the teaching process. For instance, Some schools offer courses such as "Learning Theory" to realize it. Situational simulation refers to that teachers construct certain situations to support students' activation of learning strategies and methods. That is to say, the teacher provides examples based on the teaching content for students, explaining the scope and conditions of strategy application, and give students sufficient opportunities to practice strategies so that they can skillfully use them. The first is to enable the student to know the relevant knowledge of SRL, while the latter is to exercise students' SRL skills. Based on the knowledge and skills of SRL, SRL is naturally formed through students' repeated use in learning activities.

Some scholars believe that cultivating students' SRL starts from two aspects: non-cognitive guidance measures and cognitive directional guidance measures. The former means that teachers can cultivate students' SRL by improving teaching philosophy, creating a relaxed learning atmosphere of equality and harmony, stimulating students' learning

ISSN: 0010-8189

(C) CONVERTER 2020

www.converter-magazine.info 
motivation and cultivating students' sense of learning responsibility. The latter means that teachers train students' SRL by guiding them to formulate study goals and plans, selecting study contents, means and strategies, checking learning results, adjusting or revising study goals, plans and tactics. The cognitive-oriented guidance measures themselves involve cognitive self-guidance tactics, which are derived from Speech self-regulation theory derived from Vygotsky. The self-regulation of speech can cultivate students' SRL (Manning, 1988) [5]. They believe that teachers should give students self-directed tips to guide students to practice on their own, making students effectively monitor and adjust their study, and thus promote their SRL. Of course, non-cognitive guidance measures are also quite important in cultivating students' SRL, which however is regarded as a measure to cultivate students' SRL consciousness by the author. Although SRL consciousness is the prerequisite for SRL development, they cannot be isolated, should penetrate and restrict each other. According to Pang Weiguo, the process of SRL is a process in which students "wish to learn", "learn", "be able to learn" and "persist in learning". In short, to cultivate students' SRL consciousness aims to deal with the problem of "willing of learning". And to cultivate students' autonomous study ability aims to deal with the problems of "learning", "ability to study" and "persistent learning". Therefore, the cultivation of students' SRL ability should start with the structure of autonomous learning ability, according to the relationship between knowledge, skills and abilities, and in accordance with the theoretical basis for the cultivation of students' SRL, to determine the methods and measures of cultivating student's SRL. Therefore, cognitive directional guiding measures should be mainly adopted to cultivate students' SRL, including the following aspects:

\section{(1) Guiding Students to Set Learning Goals and Plans to Improve Self-orientation Ability}

The teachers should instruct the student to analyze their own demands and formulate specific and feasible study goals and detailed learning plans according to the learning tasks before the beginning of specific learning. Teachers and students can also work together to develop a learning plan, which generally includes the choice of learning content, methods, and the arrangement of learning time. To supervise students to set study goals, the original teaching sequence can be adjusted appropriately in the teaching activities. Such as, when starting a new chapter, the teachers indicate the key points, difficulties and objectives to be achieved as well as the required background knowledge, which will benefit the formulation of students' learning objectives and plans. Only after mastering these specific information can students set learning goals that truly stimulate internal motivation.In this way, it is easy to ask students to make detailed learning plans under the guidance of learning objectives, and they are willing to follow the learning plans and actively engage in new learning activities.

\section{(2)Instructing Students to Monitor the Learning Process and Developing Self-monitoring Ability}

Monitoring is one of the meta-cognitive tactics and a key skill in SRL. In the process of SRL, the student frequently check the implementation of phased goals, study progress and achievements. Monitoring aims to check the implementation of tasks to see whether the use of time and resources is reasonable and the progress of study. Generally speaking, self-monitoring is required in whole study process. The teachers should guide students use the objectives they have set to guide their study process, and frequently check how well they have implemented their plans and achieved their objectives during the learning process. Taylor (1984) also thought it would be a good idea for students to sign a personal learning contract with themselves.

There are always difficulties in the process of learning, so it is very important to develop students' will to overcome them. It is believed that students should be trained in various kinds of thought control strategies from their implicit and explicit self-control processes to improve their self-monitoring ability.

(3)Instructing students to use feedback information to continuously enhance their self-regulation ability Self-regulation is a self-remedial process that adjusts the study progress according to the results of self-monitoring or brings the learning process that deviates from the goal back to the normal learning track, including self-feedback that gives feedback to the learning situation according to the expected learning results or objectives and self-remediation that adjusts the inappropriate learning steps, learning strategies, etc. according to the results of self-feedback.

ISSN: 0010-8189

(C) CONVERTER 2020

www.converter-magazine.info 
Teachers should instruct students to actively find out the reasons and problems in time, adjust or modify their original learning objectives, plans, adjust or modify or even interrupt their original learning strategies and procedures based on the information obtained during the inspection. Self-monitoring and regulation of learning refers to the meta-cognitive process that directs the learning process and is the basic component process of SRL. Therefore, in the process of training students' SRL, full attention should be paid to enable students to form their meta-cognitive awareness, enrich their meta-cognitive knowledge and internalize their meta-cognitive experience so as to develop their meta-cognitive ability.

(4) Guiding Students in Self-reflection and Summary to Develope Their Self-evaluation Skill After the completion of the learning activities, it is the most important factor to improve the students' SRL to reflect and summarize the learning process in depth. Teachers should help students review and reflect on each step in the process of SRL, which includes initial goal setting, selection of learning strategies and attribution of learning results, and summarize the efforts and achievements made by students in this process, so as to learn from reflection and accumulate experience. In the process of self-evaluation, students can constantly reflect on themselves and improve themselves to reach the goal of transforming from specific learning activities to abstract experiences, and to complete the process of internalizing the cognitive structure from external situations to minds, so that they can correctly evaluate themselves and raise the ability of self-evaluation.

In a word, the students' SRL directly affects their learning effectiveness. Cultivating the students' SRL should become an important task of current school education and attract the attention of educators. The cultivation of SRL should be penetrated into classroom teaching, opening with developing students' self-direction, self-monitoring, self-regulation and self-evaluation ability, so as to promote the development of students' SRL.

Teaching Reform Subject of Hunan Universities in 2019 (X.J.T. [2019] No. 815): A Comparative Research and Practice on Pre-service Teacher Training Model under the Background of Teacher Qualification Certification

\section{Acknowledgement}

This paper is funded by Social Science Project of Chenzhou Investigation and Countermeasure Research on the Current Situation of Aesthetic Education in Chenzhou City Primary Schools as a staged outcome, C.S.G. [2017] No. 1 (Czssk12017027); 2020 Hunan Province General University Teaching Reform Research Project: Reform of the Talent Training Model for Excellent Teacher Students in Local Universities [HNJG-2020-0913, Xiang Jiao Tong [2020] No. 232]; 2019 Hunan Province General University Teaching Reform Research Project: The Comparative Research and Practice of Pre-service Teacher Training Mode under the Background of Teacher Qualification Certification [HNJG-2019-291, Xiang Jiao Tong [2019] No. 815].

\section{References}

[1] W. F. Qiao, W. T. Liu, M. L. Li. Online Teaching in the Eyes of Students: Behaviors, Effects and Challenges - Based on the Online Learning Behavior Survey of Tsinghua University Students during the COVID-19 Period. Tsinghua Journal of Education, 01, 2021.

[2] W. G. Ji, M. Li, X. H. Shang. Theoretical Construction of Primary and Secondary School Students 'Autonomous Learning Ability. Journal of The Chinese Society of Education, S2, 2020.

[3] W. G. Pang. Self-regulated Learning: the Principles and Strategies of Teaching and Learning. Shanghai: East China Normal University Press, 2003.

[4] G. T. Zhou. The Relationship between the Application of Self-Regulated Learning Strategies and Academic Achievement of Junior Middle School Students. Journal of Psychological Science. 5, 2005.

[5] Manning, B.H. Cognitive Self-Instruction for Classroom Processes.State University of New York Press, 1991.

ISSN: 0010-8189 
CONVERTER MAGAZINE

Volume 2021, No. 2

ISSN: 0010-8189

(C) CONVERTER 2020

431

www.converter-magazine.info 